\title{
Odor Concentration Change Coding in the Olfactory Bulb
}

\author{
Ana Parabucki, ${ }^{1}$ Alexander Bizer, ${ }^{1}$ Genela Morris, ${ }^{1}$ Antonio E. Munoz, ${ }^{2}$ Avinash D. S. Bala, ${ }^{2}$ Matthew \\ Smear, ${ }^{2,3}$ and ${ }^{-}$Roman Shusterman ${ }^{1,2}$
}

https://doi.org/10.1523/ENEURO.0396-18.2019

${ }^{1}$ Sagol Department of Neurobiology, University of Haifa, Haifa 3498838, Israel, ${ }^{2}$ Institute of Neuroscience, University of Oregon, Eugene, OR 97403, and ${ }^{3}$ Department of Psychology, University of Oregon, Eugene, OR 97403

\begin{abstract}
Dynamical changes in the environment strongly impact our perception. Likewise, sensory systems preferentially represent stimulus changes, enhancing temporal contrast. In olfaction, odor concentration changes across consecutive inhalations $\left(\Delta C_{t}\right)$ can guide odor source localization, yet the neural representation of $\Delta C_{t}$ has not been studied in vertebrates. We have found that, in the mouse olfactory bulb, a subset of mitral/tufted (M/T) cells represents $\Delta C_{t}$, enhancing the contrast between different concentrations. These concentration change responses are direction selective: they respond either to increments or decrements of concentration, reminiscent of ON and OFF selectivity in the retina. This contrast enhancement scales with the magnitude, but not the duration of the concentration step. Further, $\Delta C_{t}$ can be read out from the total spike count per sniff, unlike odor identity and intensity, which are represented by fast temporal spike patterns. Our results demonstrate that a subset of $M / T$ cells represents $\Delta C_{t}$, providing a signal that may instruct navigational decisions in downstream olfactory circuits.
\end{abstract}

Key words: contrast; dynamical stimulus; electrophysiology; mitral and tufted cells; olfactory bulb

\section{Significance Statement}

As an animal tracks an odor plume, concentration changes over time. Here, we show that olfactory bulb neurons explicitly represent concentration changes between consecutive inhalations. This response property enhances temporal contrast, as in other sensory systems. Fine temporal spike patterns do not improve concentration change decoding. These signals may guide olfactory navigation in the natural environment.

\section{Introduction}

The brain must track how external information changes with time (Wertheimer, 1912; Bregman, 1994). Correspondingly, sensory circuits deploy specialized cell types

Received October 14, 2018; accepted January 16, 2019; First published February 01, 2019.

The authors declare no competing financial interests.

Author contributions: A.P. and R.S. designed research; A.B., R.S., A.P., A.E.M., A.D.S.B. performed research; R.S. analyzed data; G.M., M.S., and R.S. wrote the paper.

This work was supported by Israel Science Foundation Grants 816/14 and 2212/14 (to R.S.), the Marie Curie Career Integration Grant 334341 (to R.S.), and the National Institutes of Health/National Institute on Deafness and Other Communication Disorders (NIDCD) Grant R56DC015584 (to R.S. and M.S.).

Acknowledgements: We thank Yashar Ahmadian and members of the Smear and Shusterman laboratories for discussions and Wolfgang Kelsch, Shawn Lockery, David McCormick, Kathy Nagel, Shy Shoham, and Mike Wehr for comments on this manuscript. for dynamic stimuli: visual neurons emphasize luminance changes and motion (Ratliff et al., 1963), auditory neurons capture amplitude and frequency modulation (Langner, 1992), and somatosensory neurons encode vibrating touch (Werner and Mountcastle, 1965; Mountcastle et al., 1967). For many animals, odor concentration changes are equally relevant, since they carry information about odor source location (Murlis et al., 1992; Ache et al., 2016). Vertebrates can localize odor sources either by compar-

Correspondence should be addressed to Matthew Smear at smear@uoregon.edu or Roman Shusterman at roma.shusterman@gmail.com. https://doi.org/10.1523/ENEURO.0396-18.2019 Copyright (C) 2019 Parabucki et al.

This is an open-access article distributed under the terms of the Creative Commons Attribution 4.0 International license, which permits unrestricted use, distribution and reproduction in any medium provided that the original work is properly attributed. 
ing between simultaneous samples from the two nostrils, or by comparing samples taken sequentially from different locations (Catania, 2013). When bilateral sampling is prevented by naris occlusion, animals are only partly impaired at localizing odor sources (Porter et al., 2007; Khan et al., 2012; Catania, 2013; Jones and Urban, 2018). Therefore, vertebrates must also sense changes of odor concentration, from sniff to sniff $\left(\Delta C_{t}\right)$, to guide them to an odor source. Yet despite this evidence that $\Delta C_{t}$ can guide odor tracking, whether olfactory neurons encode sniff to sniff changes has not been directly addressed.

Unlike invertebrate olfactory systems, in which olfactory sensory neurons (OSNs) are continuously exposed to the medium, air-breathing vertebrates discretize the input to OSNs into intermittent inhalations. In this case, the brain must maintain a memory of odor concentration across the exhalation interval to compute $\Delta C_{t}$.

How and where does the olfactory system solve this problem? We demonstrate here that a subset of neurons in the olfactory bulb encode $\Delta C_{t}$ on the time scale of a single sniff. Thus, like their counterparts in other sensory systems such as ON/OFF responses in vision (Kuffler, 1953; Schiller, 1992; Westheimer, 2007), a subset of olfactory neurons represents stimulus increments and decrements. Further, these representations depend on the magnitude of the concentration step, but not the duration of the step (i.e., for how many sniffs it lasts). Lastly, while fast temporal spike patterns can improve decoding of absolute concentration, concentration changes can be read out from total spike count.

\section{Materials and Methods}

\section{Animals}

Data were collected in seven C57BL/6J male mice. Subjects were 8-16 weeks old at the beginning of recordings and were maintained on a 12/12 h light/dark cycle (lights on at 8 P.M.) in isolated cages in an animal facility. All animal care and experimental procedures were in accordance with a protocol approved by the University of Haifa and University of Oregon Institutional Animal Care and Use Committees.

\section{Surgery}

Mice were anesthetized using isofluorane gas anesthesia, and a head plate and a pressure cannula were implanted. For sniffing cannula implantation, we drilled a small hole in the nasal bone, into which the thin 7- to 8-mm-long stainless-steel cannula (gauge 23 capillary tubing, Small Parts) was inserted, fastened with glue, and stabilized with dental cement (Verhagen et al., 2007). A small craniotomy was performed above one of the olfactory bulbs, contralateral to the side of sniffing cannula implantation. The reference electrode was implanted in cerebellum. At the end of the procedure, the craniotomy was covered with a biocompatible silicone elastomer sealant (Kwik-cast, WPI). The mice were given $3 \mathrm{~d}$ after a surgery for recovery.

\section{Odor delivery}

For stimulus delivery, we used a custom eight-odor air dilution olfactometer, based on a previous design (Bodyak and Slotnick, 1999). When no odor was being presented to the mouse, a steady stream of clean air (1000 $\mathrm{ml} / \mathrm{min}$ ) was flowed to the odor port. During odorant presentation, $\mathrm{N}_{2}$ flowed through the selected odorant vial. We used multiple odorants obtained from Sigma-Aldrich. The odorants were stored in liquid phase (diluted either 1:5 or 1:10 in mineral oil) in dark vials. We used acetophenone, amyl acetate, geraniol, ethyl acetate, S-limonene, methyl butyrate, menthone, methyl salicylate, pentyl acetate, and vanillin as odorants. The odorant concentration delivered to the animal was reduced additional tenfold by air dilution and homogenized in a long Teflon tube before reaching the final valve. After sufficient mixing and equilibration time, the dual three-way Teflon valve (SH360T042; NResearch) directed the odor flow to the odor port and diverted the clean airflow to the exhaust. All air flows and line impedances were equalized to minimize the pressure transients resulting from odor and final valve switching. The time course of odor concentration was checked by Photo-Ionization Detector (200B mini-PID; Aurora Scientific). The concentration reached a steady state $\sim 40$ ms after final valve opening (Resulaj and Rinberg, 2015). Further, to change odor concentration, we passed stable odorized airflow through a concentration change manifold (CCM; Fig. 1A). Odor concentration changes were achieved by activating a pair of matching solenoids (LHQA2411220H; The Lee Company) which performed air dilution. For each pair of solenoids, one valve was connected to a vacuum channel and the other to a clean airflow channel. Solenoid activation in the vacuum channel diverted part of the odorized air, while solenoid activation in the air channel contributed an equal amount of flow back into the system. To maintain constant total airflow (Extended Data Fig. 1-1B), the impedance of each air channel was matched to the impedance of the corresponding vacuum channel using manual needle valves R1-R3 (NV3H-1012-3-S; Beswick Engineering). To ensure that the temporal profile of odor concentration stabilized before inhalation began, we predominantly used odorants with higher vapor pressure (Martelli et al., 2013). For these high vapor pressure odorants, the stimulus reaches $95 \%$ of final concentration in $20-40 \mathrm{~ms}$ (Fig. 1C).

\section{Electrophysiological recording}

We recorded mitral/tufted (M/T) cell activity using acute 16- or 128-channel matrix array of Si-probes (a2x2-tet3mm-150-150-121-A16, M4x8-5mm-Buz-200/300um; NeuroNexus). Cells were recorded in both ventral and dorsal mitral cell layers. The data were acquired using a 128-channel data acquisition system (RHD2000; Intan Technologies) at $20-\mathrm{kHz}$ sampling frequency. To monitor sniffing, the intranasal cannula was connected to a pressure sensor with polyethylene tubing (801000; A-M Systems). The pressure was measured using a pressure sensor (24PCEFJ6G; Honeywell). The amplified output signal from the pressure sensor was recorded in parallel with electrophysiological data on one of the analog input channels. 
A

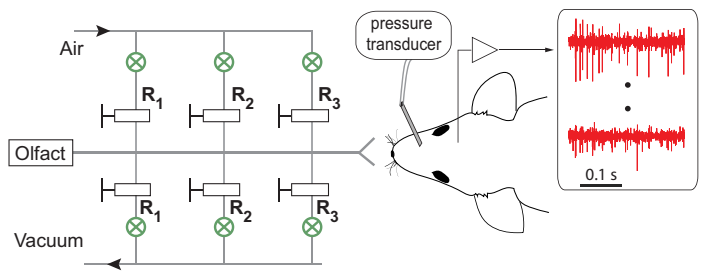

C

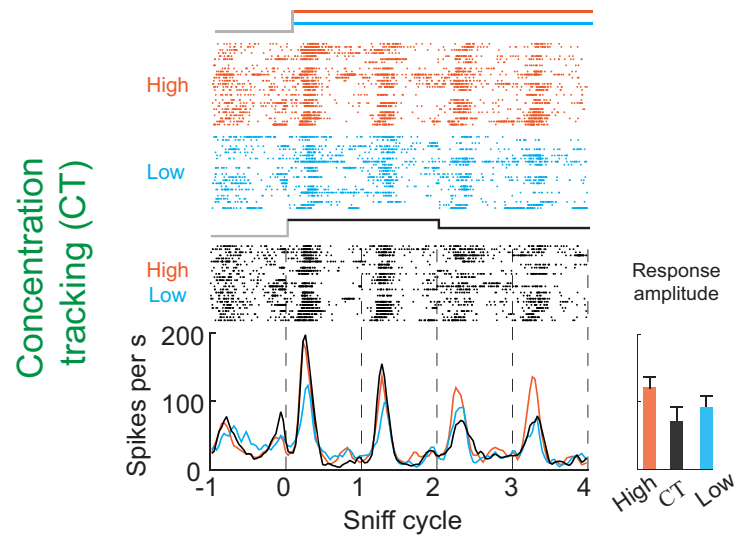

E

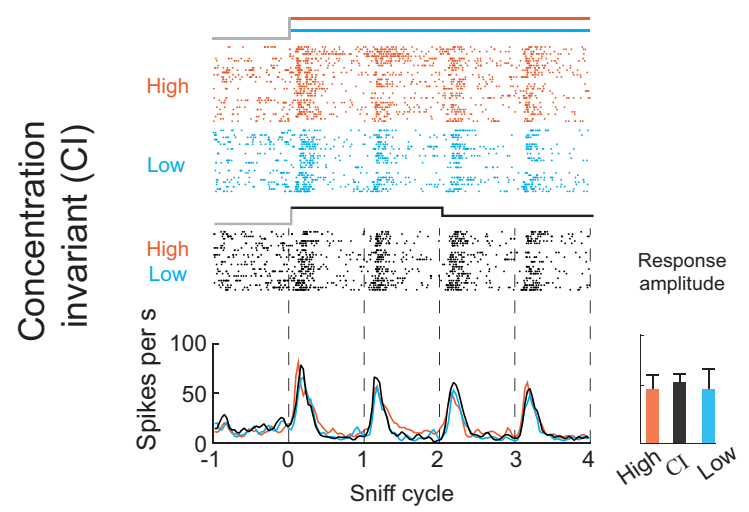

B

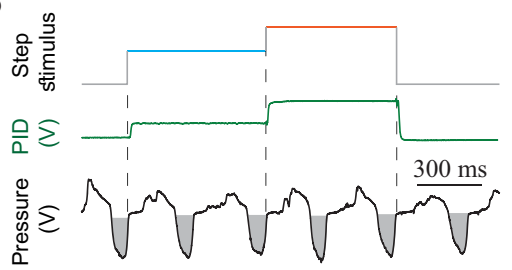

D

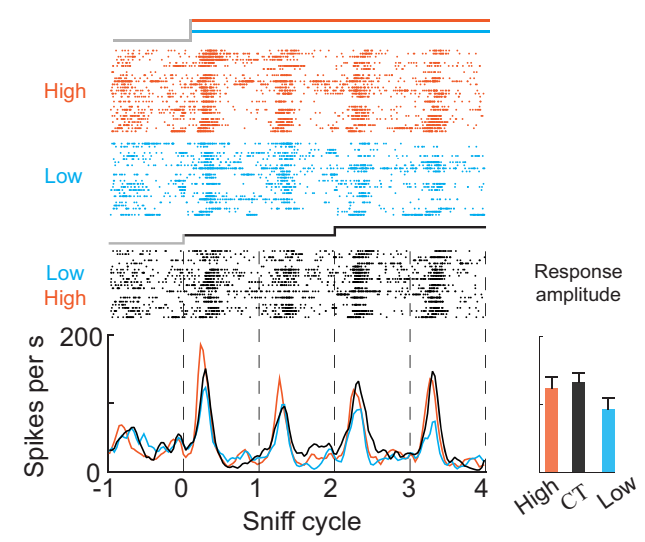

$\mathbf{F}$

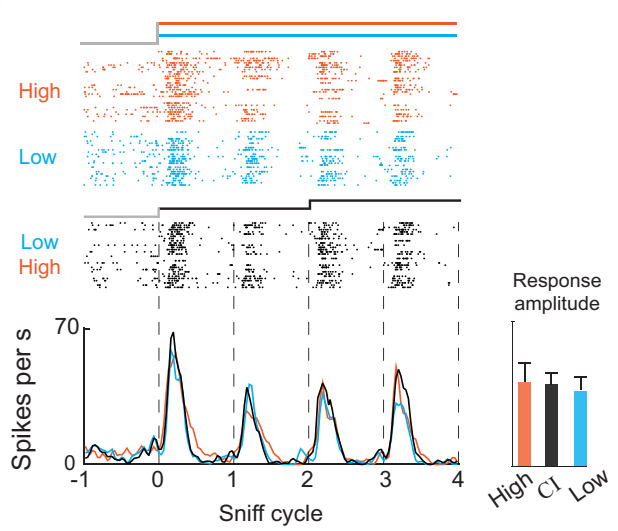

Figure 1. $C T$ and $\mathrm{Cl}$ odor responses. $\boldsymbol{A}$, Schematic of the experiment. Right, A head-fixed mouse implanted with an intranasal cannula and a multi-electrode chamber was positioned in front of the odor delivery port. Left, CCM. B, Odor concentration step paradigm. Odor concentration changes every two sniff cycles. Green curve indicates the response of a photoionization detector (PID) to presentation of ethyl acetate. Sniff waveforms (black) are shown below the plots. Gray areas indicate inhalation. Vertical dashed lines indicate onset of concentration changes. $\boldsymbol{C}, \boldsymbol{D}$, Examples of $C T$ responses from two cells. Raster and PSTH plots of M/T cell response to static high concentration (orange), static low concentration (blue), and concentration step stimuli (black). The responses of these cell odor pairs change with odor concentrations the same way in both static and step stimuli. Bar graph on right shows peak response amplitudes on the third sniff cycle for each stimulus. Error bars indicate SD (see Materials and Methods). E, F, Same as $\boldsymbol{C}, \boldsymbol{D}$ but for two cell-odor pairs that are invariant to odor concentration in the presented range.

Before recording began, the mice were first adapted to head fixation. Mice typically remained quiescent after one to two sessions of head fixation, after which recording sessions started. We presented two to three odors in a single session in pseudo-random sequence with an average interstimulus interval of $7 \mathrm{~s}$. Each odor was presented in four temporal patterns: (1) static high, high concentration $(\sim 1-2 \%$ of saturated vapor pressure) of odor for four sniff cycles; (2) static low, low concentration (50\% of high concentration level) for four sniff cycles; (3) a step from high to low, for the first two sniff cycles, concentration level was equal to the level of static high, after which the concentration stepped to the low concentration; and (4) a step from low to high, two sniff cycles of low concentration followed by two sniffs of high concentration. We controlled odor concentration using a $\mathrm{CCM}$. Odor onsets and concentration changes were triggered at the beginning of the exhalation phase, which occur at positive-going zero crossings of the pressure signal. Since odor cannot orthonasally enter the nose during exhalation, triggering by exhalation onset allows enough time for the odor stimulus to reach a steady state of concentration by the time the animal begins to inhale. One session usually lasted for $60-90 \mathrm{~min}$ and consisted of 300-400 trials. 
Table 1. Statistical table

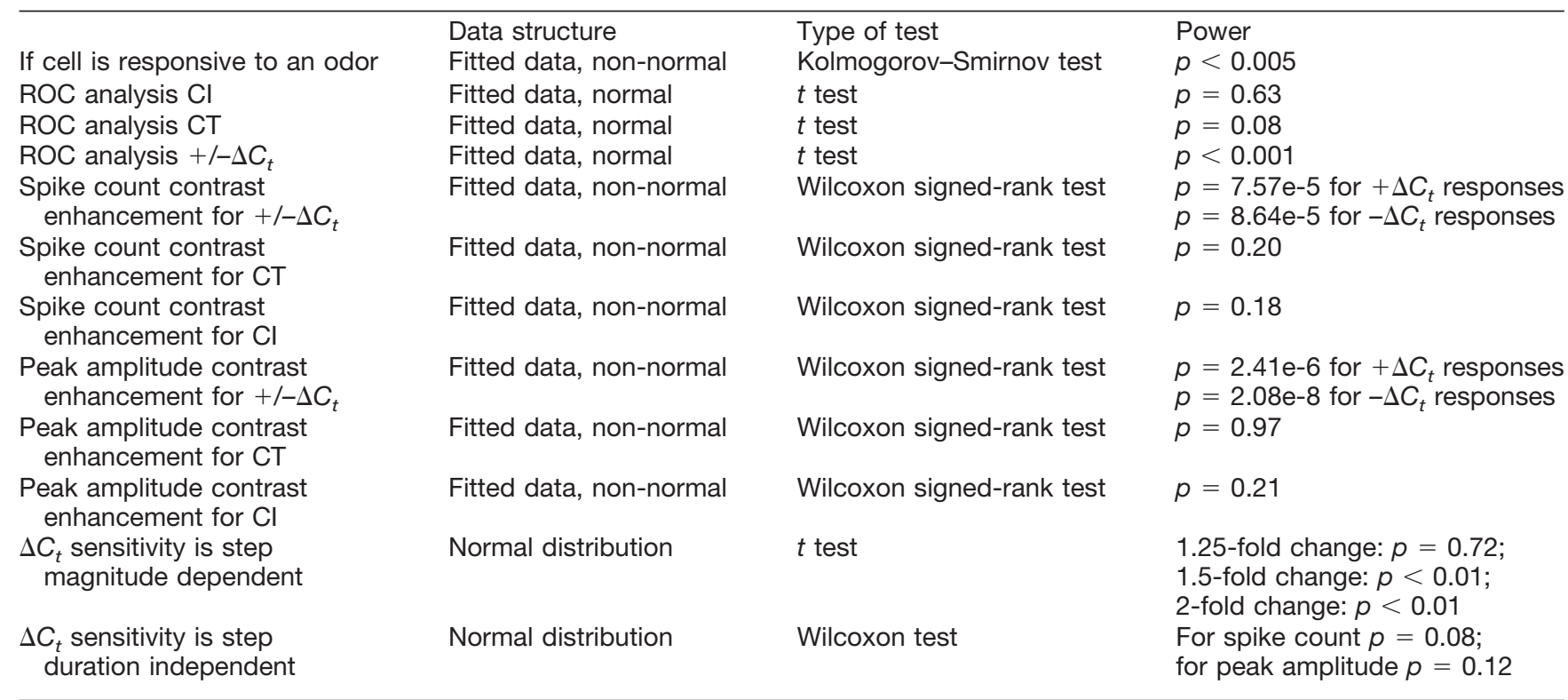

\section{Spike extraction and data analysis}

All analysis was done in MATLAB (MathWorks). Electrophysiological data were filtered between $300 \mathrm{~Hz}$ and 5 $\mathrm{kHz}$ and spike sorted. For spike sorting we used software package written by Alex Koulakov (Shusterman et al., 2011; Table 1)

\section{Temporal alignment of responses}

For analysis, sniffing traces were down-sampled to 1 $\mathrm{kHz}$, and filtered in the range of $0.5-30 \mathrm{~Hz}$. The inhalation onset and offset were detected by zero crossings of a parabola fit to the minima of the pressure signal following the onset of the inhalation. Inhalation onset/offset was defined as the first zero crossing of the parabola (Shusterman et al., 2011). We defined two intervals: the first is from inhalation onset to inhalation offset and the second is the rest of the sniffing cycle, from the inhalation offset to the next inhalation onset. While the duration of the first interval is concentration independent, the duration of the second interval depends on the concentration of presented odor (Extended Data Fig. 5-1). To compare neuronal responses across trials and concentrations, we morphed the inhalation part of the sniff cycle and corresponding spike train to the average one (Shusterman et al., 2011). The second part of the sniff cycle and corresponding neural activity were matched to the average over trials: longer cycles were truncated and shorter were zero padded.

\section{Odor responses}

To establish whether a cell is responsive to an odor, we compared the cumulative distribution of the neuronal spikes without odors to the cumulative distribution of neuronal activity during the first odorized sniff cycle, using the Kolmogorov-Smirnov test. Neuronal activity without odor was sampled from three sniffs preceding odor delivery across all trials. Neuronal activity for a given odor was sampled from the first sniff after stimulus onset. Cells were considered responsive if the distribution of spiking activity during the first odorized cycle statistically differed from the distribution of baseline responses in at least one 10 -ms bin relative to inhalation onset $(p<0.005$; Benjamini-Hochberg multiple comparison correction) or if their average spike rate over the sniff cycle differed significantly from baseline $(p<0.05)$.

\section{Recovery index (RI)}

To measure how $\Delta C_{t}$ cell-odor pairs recover in sniffs after the concentration step, we quantified a RI, using the peak amplitude of the response. For positive $\Delta C_{t}$ responses, it consists of the ratio between change of response between two consecutive sniff cycles after the concentration change (LH3-LH4) to the difference between $\Delta C_{t}$ response and the response on the matching static stimulus $(\mathrm{LH} 3-\mathrm{H} 3)$ :

$$
\frac{L H 3-L H 4}{L H 3-H 3}
$$

If the $\mathrm{M} / \mathrm{T}$ cell responds with identical amplitude on two sniff cycles following the concentration step, this will lead to $\mathrm{LH} 4=\mathrm{LH} 3$, the numerator will be zero and thus $\mathrm{RI}=0$. In the other limiting case, when the response on the second sniff following the step (LH4) is equal to the static response $(\mathrm{H} 3)$, the denominator will be equal to the numerator and therefore $\mathrm{RI}$ will be equal 1 . Therefore, most of the RIs will be distributed between 0 and 1 .

By analogy, for negative $\Delta C_{t}$ responses, $\mathrm{Rl}$ will take the following form:

$$
\frac{H L 3-H L 4}{H L 3-L 3}
$$

\section{ROC analysis of contrast enhancement}

$\mathrm{ROC}$ analysis provides a measure of how well a given cell-odor pair can discriminate between two stimuli. To measure the discriminability between the static odor stim- 
uli, high and low, we compute the area under the ROC curve (auROC) for the distributions of spike counts over the third sniff of each stimulus (Extended Data Fig. 4-2A1,B1,C1; Green and Swets, 1966). ROC curves were created by plotting the probability that the single-trial spike count (Extended Data Fig. 4-2A2) exceeds a given value (Extended Data Fig. 4-2A3,B3,C3) for two stimulus types. For each point, on the $x$-axis is the probability for one stimulus type, on the $y$-axis is the probability for another stimulus type. Dark curves show the probabilities for dynamic versus static, while lighter curves show the probabilities of static high versus static low. An auROC value of 1 indicates no overlap between the two distributions, while a value of 0.5 indicates complete overlap between the two distributions. We then plot the static stimulus auROC against the $\Delta C_{t}$ discriminability (Extended Data Fig. 4-2D,E). This plot shows whether a given cell-odor pair shows contrast enhancement between concentrations during step stimuli.

Three example cell-odor pairs are shown in such a plot (Extended Data Fig. 4-2A-C). Cl responses do not discriminate between high and low concentration ( $t$ test, $p=$ 0.63 ), and give values of near 0.5 for both static and flickering stimuli (Extended Data Fig. 4-2E). CT responses discriminate equally well between static and flickering stimuli, and thus fall along the diagonal of this plot ( $t$ test, $p=0.08) . \Delta C_{t}$ responses discriminate better between dynamic and static stimuli than between two static stimuli, so that they fall above the diagonal ( $t$ test, $p<0.001$ for both $+\Delta C_{t}$ and $-\Delta C_{t}$ ). These analyses demonstrate that $\Delta C_{t}$ sensitivity enhances the contrast between concentrations, potentially facilitating detection of concentration change.

\section{Odor concentration classification analysis}

To estimate how well single neurons $(n=49)$ can discriminate between two odor concentrations on a trial by trial basis, we constructed a Mahalanobis distance linear classifier. For concentration discrimination, we calculated discriminability between responses to static high and static low on the 3rd sniff cycle, $\mathrm{L}_{3}$ and $\mathrm{H}_{3}$. For every cell and for every pair of concentrations we counted spikes using multiple time bins $(5,10,20,40,80$, and 160 $\mathrm{ms}$ ). Single trials were randomly selected and compared to a set of templates constructed from $70 \%$ of trials for each of the two concentrations. We used the mahal function in MATLAB to estimate Mahalanobis distance from each single trial vector to two groups of multiple trial templates representing two concentrations. This procedure was repeated 300 times for different single trial population vectors and was repeated for each bin size.

A similar analysis was performed on the same cell-odor pairs to estimate discriminability in $\Delta C_{t}$. For $\Delta C_{t}$ discrimination, we calculated discriminability between $\mathrm{LH}_{3}$ and $\mathrm{L}_{3}$ sniffs for $+\Delta C_{t}$ responses and $\mathrm{HL}_{3}$ and $\mathrm{H}_{3}$ sniffs for $-\Delta C_{t}$ responses.

\section{Behavioral experiments}

Two mice were implanted with a head bar and a cannula in their nose, both secured to the skull by dental cement (Smear et al., 2011). After recovery from surgery, mice were water restricted so that they are motivated to work for water reward during behavioral testing.

To measure $\Delta C_{t}$ sensitivity, we used a Go/No-Go paradigm (Smear et al., 2011). Trial events were controlled and behavioral outputs (sniffing and licking) were measured using MATLAB and a custom-built Arduino-based behavior-control system. Stimulus presentation is synchronized to the sniff cycle, such that changes in odor concentration only occur while the animal is exhaling. Thus, there is no change in odor concentration during inhalation, and the animal must compare two discrete odor samples across time to detect any changes in odor concentration.

Mice were initially trained in a simple odor detection task, in which they are supposed to lick when odor is presented, and not lick when a blank stimulus occurs. After they have acquired at least $90 \%$ performance in this task, they begin $\Delta C_{t}$ training. In the second phase of training, mice were trained to report positive or negative $\Delta C_{t}$ relative to an absolute concentration, $C$. All trials start by delivering the baseline concentration $C$ to the subject during the first sniff. During the second sniff, however, the concentration can either change $\left(C+\Delta C_{t}\right.$ or $C-\Delta C_{t}$; No-Go trials) or stay at $C$ (Go trials). Trials containing the $\Delta C_{t}$ signal are used as No-Go trials, because in a Go/ No-Go task most errors are false alarms. By delivering $\Delta C_{t}$ stimuli during No-Go trials, we ensure that the majority of errors occur during $\Delta C_{t}$ trials, making these trials more informative. Responses are classified into correct-hits $(\mathrm{H}$ : Go trial, mouse licks), correct rejections (CR: No-Go trial, mouse does not lick), and incorrect-false alarms (FA: No-Go trial, mouse licks) and misses (M: Go trial, mouse does not lick).

\section{Results}

\section{Experimental setup and response types}

We recorded respiration and $\mathrm{M} / \mathrm{T}$ cell activity (seven mice, 92 cells, 242 cell-odor pairs) in awake, head-fixed mice (Fig. $1 A$ ). To rapidly change odor concentration, we developed a novel CCM, with which rapid concentration changes were achieved by air dilution (Fig. $1 A$; Materials and Methods). Sniffing was measured through an intranasal pressure cannula (Fig. 1A). Using real-time closedloop odor presentation, we switched odor concentrations at the beginning of the exhalation phase so that the stimulus reached its new steady state concentration before the onset of the next inhalation (Fig. 1B; Extended Data Fig. 1-1).

In most experiments, we presented odorants in two static concentration patterns: high $(\mathrm{H})$ and low $(\mathrm{L})$, and two dynamic patterns: a step from high to low $(\mathrm{HL})$ and a step from low to high (LH). The high concentration was twice that of the low concentration, a concentration difference that is within the range of concentration changes that would be encountered in turbulent plumes (Crimaldi et al., 2002; Gaudry et al., 2012; Gire et al., 2016). Behavioral testing in a Go/No go paradigm confirmed that 2-fold concentration steps are perceptible to mice (Extended Data Fig. 1-2). 
A

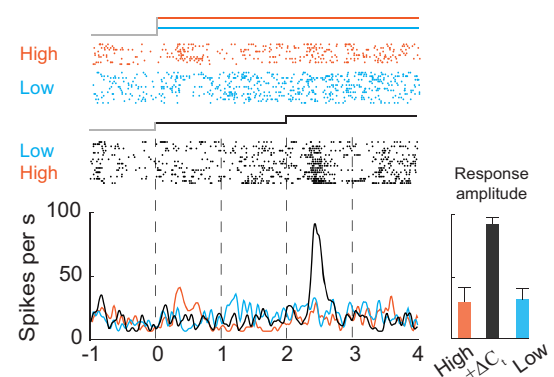

C

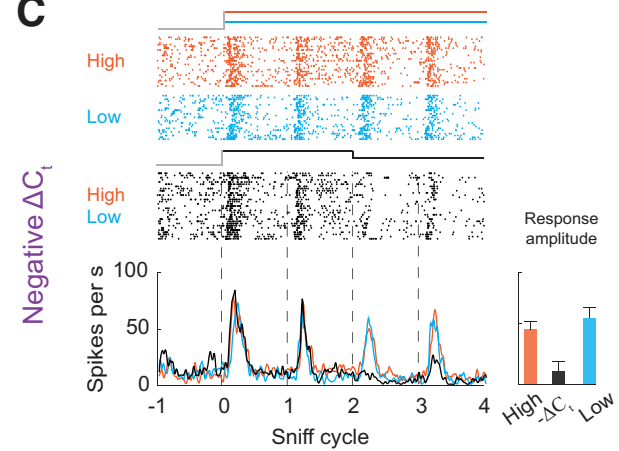

B

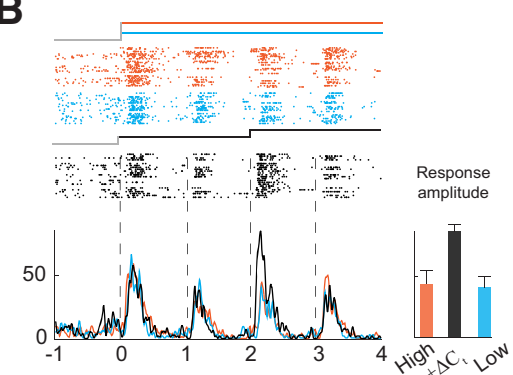

D

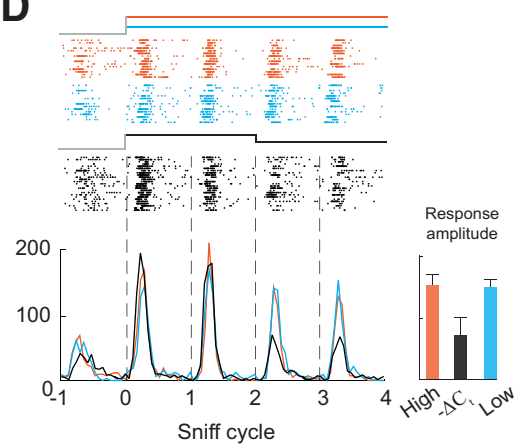

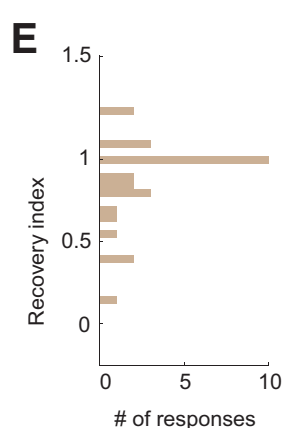

F

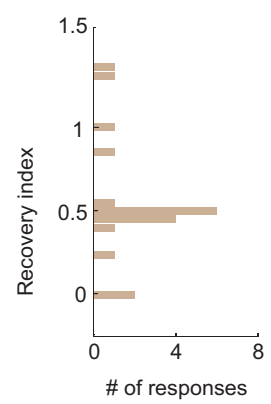

Figure 2. $\mathrm{M} / \mathrm{T}$ cells responsive to changes in odor concentration. $\boldsymbol{A}, \boldsymbol{B}$, Examples of $+\Delta \boldsymbol{C}_{t}$ responses. Raster and PSTH plots of two $\mathrm{M} / \mathrm{T}$ cell's responses to static high concentration (orange), static low concentration (blue), and low to high (black). Bar graph on right shows peak response amplitudes on the third sniff cycle for each stimulus. Error bars indicate SD. $\boldsymbol{C}, \boldsymbol{D}$, Examples of $-\Delta C_{t}$ responses. Raster and PSTH plots of two M/T cell's responses to static high concentration (orange), static low concentration (blue), and high to low stimulus (black). $\boldsymbol{E}, \boldsymbol{F}$, Distribution of recovery indices for $+\Delta C_{t}$ and $-\Delta C_{t}$ responses, respectively. A value of 1 indicates complete recovery to the static odor stimulus response, while a value of 0 indicates no recovery.

Step stimuli consisted of a presentation of one concentration for two sniff cycles, followed by a switch to the other concentration. These stimuli evoked three different response types across odor-cell pairs. For some cell-odor pairs, spiking responses were proportional to odor concentration on the current sniff but were not affected by odor concentration on previous sniffs. Thus, these concentration-tracking cell-odor pairs $(C T$; Fig. $1 C, D)$ faithfully represented the concentration on each sniff. For other cell-odor pairs, the response did not change across concentrations for static or step stimuli. We refer to these as concentration-invariant (Cl; Fig. 1E,F). These unchanging responses may be specialized for odor identification, for which concentration invariance is an important property (Wilson and Mainen, 2006; Shusterman et al., 2018; Wilson et al., 2017; Bolding and Franks, 2018). However, testing with a wider range of concentrations would be needed to fully determine these cells' concentration response function for a given odor. Lastly, we observed responses that were sensitive to changes in odor concentration $\left(\Delta C_{t}\right.$; Fig. 2). For these cell-odor pairs, responses to step stimuli could not be predicted from responses to static stimuli. These $\Delta C_{t}$ cell-odor pairs responded to $\mathrm{LH}$ $\left(+\Delta C_{t}\right.$ responses; Fig. $2 A, B$; Extended Data Fig. $2-1 A$ ) or to $\mathrm{HL}$ stimuli $\left(-\Delta C_{t}\right.$ responses; Fig. $2 C, D$; Extended Data Fig. 2-1A). For example, such a cell-odor pair may exhibit an identical response to static high and static low stimuli but respond differently when these same concentrations are alternated in the HL stimuli (Fig. $2 C, D$ ). Because of this history dependence, such a response carries information about concentration change rather than the concentration per se. The majority of $\Delta C_{t}$ responses were selective for the direction of change (41/49; Extended Data Fig. 2-2). Further, almost all $\Delta C_{t}$ responses increased firing rate with positive concentration changes and decreased firing rate with negative changes (46/49). Strikingly, $25 \%$ of the $+\Delta C_{t}$ responses did not respond to the initial stimulus onset (first sniff), a change from no odor to odor, but only after the upward step in concentration (7/28; Fig. 2A).

For a cell to reliably report $\Delta C_{t}$ with single sniff temporal resolution, its response should only be detectably different in the sniff that immediately follows the concentration change. On the next sniff, the response should return to the level evoked by static stimuli. To quantify the extent of recovery to the static level on the second sniff after the concentration change, we devised a RI (see Materials and Methods; Extended Data Fig. 2-3). This index ranges from 1 for complete recovery to 0 for no recovery to the static stimulus response (Fig. 2E,F). While $+\Delta C_{t}$ responses mostly recovered near to the static level (Fig. 2E), $-\Delta C_{t}$ responses do not recover completely (Fig. $2 F$ ).

All responses were classified as $\Delta C_{t}, C T$, or Cl. To categorize each response, we tested whether the cumulative distribution of spike count after inhalation onset differed between stimuli (Kolmogorov-Smirnov test; Fig. $3 A$; see Materials and Methods). This statistical test is sensitive not only to changes in the total number of spikes within a sniff cycle but also to temporal redistribution of spikes within the cycle. Importantly, due to adaptation, both representation of odor concentration (Cang and 
A

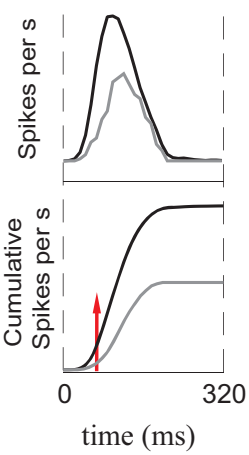

C

\begin{tabular}{l|c|c|} 
& $\mathrm{L}_{1}=\mathrm{H}_{1}$ & $\mathrm{~L}_{1} \neq \mathrm{H}_{1}$ \\
\hline $\mathrm{HL}_{3}=\mathrm{H}_{3}$ & $C I$ & - \\
$\mathrm{HL}_{3}=\mathrm{L}_{3}$ & $C I$ & \\
\hline $\mathrm{HL}_{3} \neq \mathrm{H}_{3}$ & $\Delta C_{t}$ & $\Delta C_{t}$ \\
$\mathrm{HL}_{3} \neq \mathrm{L}_{3}$ & & \\
\hline $\mathrm{HL}_{3}=\mathrm{H}_{3}$ & $\Delta C_{t}$ & $\Delta C_{t}$ \\
$\mathrm{HL}_{3}^{3} \neq \mathrm{L}_{3}$ & & $C T$ \\
$\mathrm{HL}_{3} \neq \mathrm{H}_{3}$ & - & $C T$ \\
$\mathrm{HL}_{3}=\mathrm{L}_{3}$ & & \\
\hline
\end{tabular}

D

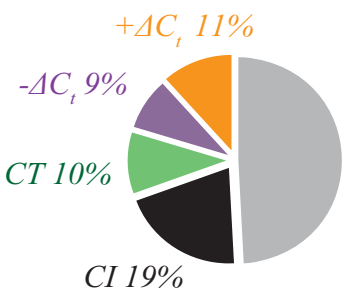

B2

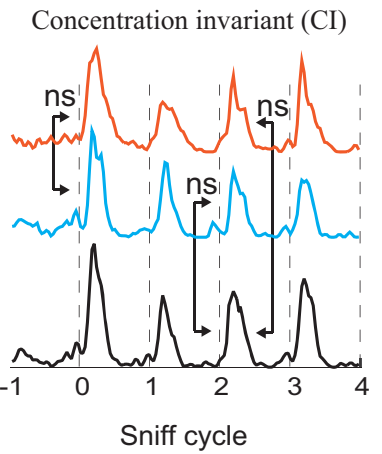

B3

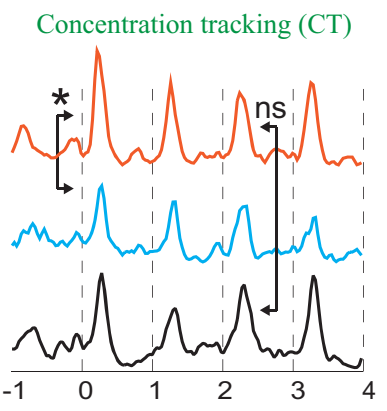

B4

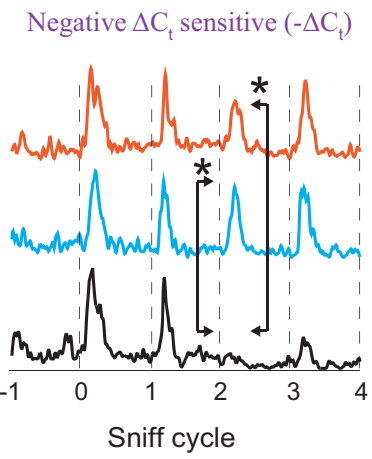

E
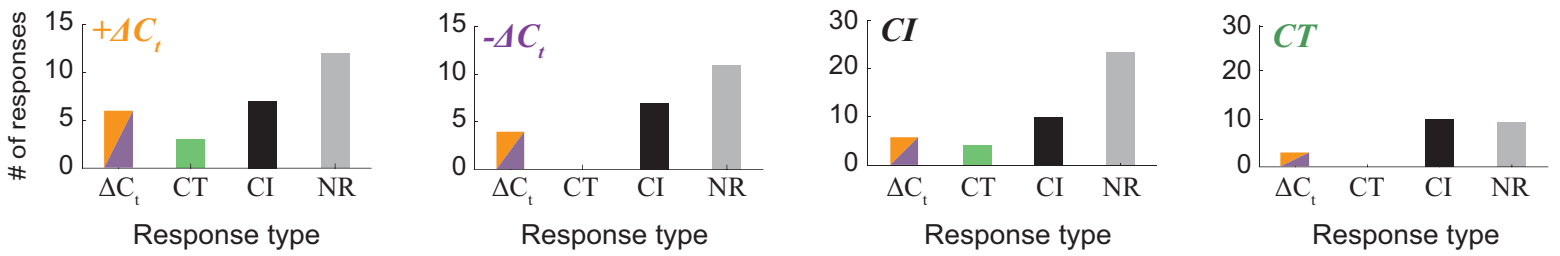

Figure 3. Categorization of response types. A, Criteria for determining whether a cell was responsive to a given odor. Top, example of excitatory odor response PSTH. The black line is a PSTH of spiking during odorized sniffs. The gray line is a PSTH during unodorized sniffs. Bottom, cumulative spike counts of data from top plot. The red line indicates the first moment when cumulative distributions with and without stimulus become statistically different. B1-B4, PSTHs from examples of each response type to high, low, and low->high stimuli are vertically separated. Arrows indicate which sniffs of the response are statistically compared. Non-significant differences are marked ns, and significant differences are marked with $*$ (Kolmogorov-Smirnov test, $p<0.01$ ). B1, A CT cell-odor pair responded differently to the two concentrations, and this difference is not affected by a concentration step. Example data are the same as Figure 1D. B2, A Cl cell-odor pair responded identically to both concentrations, with or without a step. Example data are the same as Figure $1 F . B 3, \Delta C_{t}$ cell-odor pairs responded differently to a given concentration after a concentration step. Example data are the same as Figure $2 B$. B4, Example $-\Delta C_{t}$ response data are the same as Figure $2 C$. $\boldsymbol{C}$, Comparisons used to categorize odor-cell pairs. $\boldsymbol{D}$, Distribution of different response types: $C l(n=49), C T(n=25)$, positive $\Delta C_{t}\left(+\Delta C_{t}, n=28\right)$, and negative $\Delta C_{t}\left(-\Delta C_{t} ; n=21\right)$. $E$, Distribution of responses to a second odor for positive $\Delta C_{t}$ (orange), negative $\Delta C_{t}$ (purple), $C l$ (black), and $C T$ (green) cell-odor pairs.

Isaacson, 2003; Sirotin et al., 2015) and perception of odor intensity (Wojcik and Sirotin, 2014) depend on the duration of odor exposure. Therefore, for all analyses, we compare responses to different stimuli on the same sniff cycle after stimulus onset (e.g., we compare the 3rd sniff of the step stimulus to the 3rd sniff of the static stimulus; see Extended Data Fig. 2-4 for an example response with strong adaptation).

Concentration tracking $(C T)$ responses differ on the first sniff of the static stimuli, but do not differ between the third sniff of step and static stimuli. (Fig. 3B1,C). A cellodor pair is categorized as $\mathrm{Cl}$ if the response on the first sniff of the static stimuli does not significantly differ between high and low, and the response on the third sniff of the concentration step stimulus does not differ from the third sniff of the two static stimuli. (Fig. 3B2,C). $\Delta C_{t}$ sensitive responses differ on the third sniff of the $\Delta C_{t}$ stimulus from the third sniff of both static stimuli. If after a positive change in concentration, the cell responded differently from its response to static high concentration, this cellodor pair was categorized as $+\Delta C_{t}$ (Fig. 3B3,C). $-\Delta C_{t}$ cell-odor pairs gave a different response to the low concentration depending on the concentration in the preceding sniff (Fig. 3B4,C). In summary, 51\% $(n=123)$ of 
A
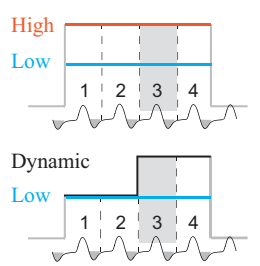

B

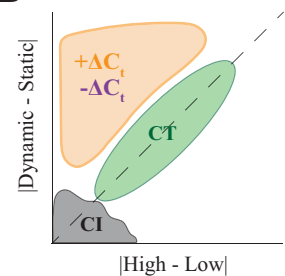

C

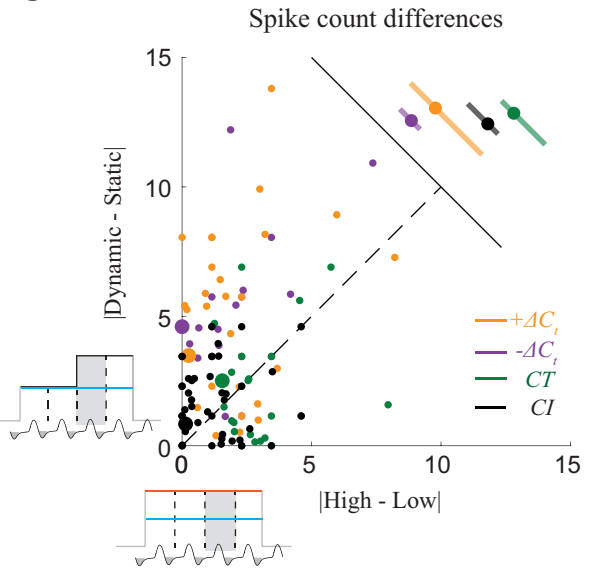

D

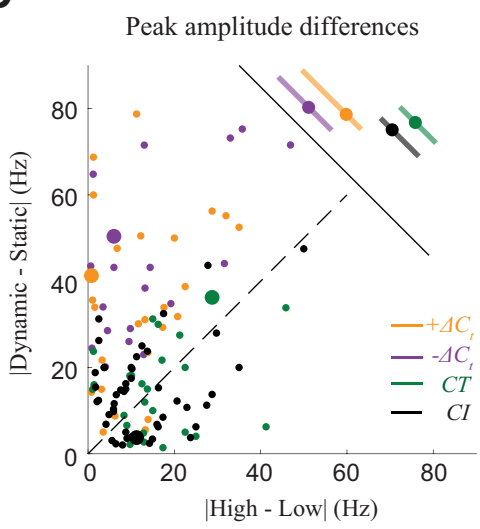

Figure 4. Contrast between concentrations depends on the stimulus history. A, Schematic of contrast comparison. To compare contrasts, for each cell-odor pair, we take the difference in response between the 3rd sniffs of the static high $(\mathrm{H})$ and static low $(\mathrm{L})$ stimuli, and plot that against the difference between the 3rd sniffs of the dynamic stimulus and the corresponding static stimulus (in this example L). Thus, only the concentration in the preceding sniff varies, and the concentrations being compared are constant. $\boldsymbol{B}$, Expected distribution of responses. CT responses will be distributed along diagonal, $C l$ responses will be distributed near the origin, and $\Delta C_{t}$ responses will be distributed above diagonal. C, Scatter plot of full sniff spike count differences between two static stimuli against differences between dynamic and static stimuli, on the 3rd sniff cycle. $C I, C T,+\Delta C_{t}$ and $-\Delta C_{t}$ are marked by black, green, orange, and blue color, respectively. Example cells from Figure 3B1-B4 are indicated by enlarged dots. Adjacent panel shows the means and STDs of the spike count differences. $\boldsymbol{D}$, Same as $\boldsymbol{C}$ for differences in the peak amplitude of the response. Example cells from Figure 3B1-B4 are indicated by enlarged dots. Adjacent panel shows the means and STDs of the peak amplitude differences. See also Extended Data Figure 4-2.

cell-odor pairs responded to the odorants we presented. Of these responsive cell-odor pairs, $41 \%$ were $\Delta C_{t}, 20 \%$ were $C T$ and $39 \%$ were $\mathrm{Cl}$ (Fig. $3 D$ ).

What is the cellular basis of $\Delta C_{t}$ sensitivity? Are there dedicated " $\Delta C_{t}$ cells" that represent concentration changes for all their effective odor stimuli, or does $\Delta C_{t}$ sensitivity depend on odor identity? To approach this question, we compared the responses of each cell to different odors (Fig. $3 E$ ). An individual cell could belong to different response types for different odors. Importantly, cells with $\Delta C_{t}$ sensitivity to one odor are not always $\Delta C_{t}$ sensitive to other odors at the tested concentrations (Fig. $3 E$ ). Therefore, $\Delta C_{t}$ sensitivity cannot be invariant to both odor identity and concentration. Further studies using a wider range of absolute concentrations will be necessary to determine whether there is invariance to either of these features.

\section{Contrast between concentrations depends on the stimulation history}

In $\Delta C_{t}$ responses (Fig. 2), the response to a given concentration depends on the concentration presented in the previous sniff. On the sniff after a concentration change, the difference between responses to different concentrations will be enlarged, thus enhancing the contrast for that sniff. Responses of $\mathrm{M} / \mathrm{T}$ cells may encode odor stimuli either by changes in spike count or by changes in temporal profile without changes in spike count (Cury and Uchida, 2010; Shusterman et al., 2011). Our method of classifying responses is sensitive not only to changes in the total number of spikes within a sniff cycle but also to temporal redistribution of spikes within the cycle. To separately quantify which features of neuronal responses contribute to contrast enhancement, we compared the difference between responses to high and low concentrations when preceded by a step to the difference when preceded by the same concentration (Fig. $4 A$ ). We plotted full sniff spike count differences between the 3rd sniffs of the two static stimuli (lhigh-lowl) against spike count differences between a dynamic step stimulus and the corresponding static stimulus (i.e., Idynamicstaticl). In this visualization, the farther a cell-odor pair is from the diagonal, the stronger its contrast enhancement (Fig. $4 B$ ). Both $+\Delta C_{t}$ and $-\Delta C_{t}$ response populations showed contrast enhancement, with responses significantly shifted from the diagonal (Wilcoxon signed-rank test, $p=7.57 * 10^{-5}$ for $+\Delta C_{t}$ and $p=8.64 * 10^{-5}$ for $-\Delta C_{t}$ responses), while the distributions for $C T$ (Wilcoxon signed-rank test, $p=0.20, n=25$ ) and $\mathrm{Cl}$ (Wilcoxon signed-rank test, $p=0.18, n=49$ ) responses are symmetric about the diagonal (Fig. 4C; Extended Data Fig. 4-1A).

To quantify how $\Delta \mathrm{C}_{t}$ sensitivity enhances sub-sniff temporal differences between odor responses, we next performed the same comparison for differences in peak amplitude (peak firing rate; Fig. 4D; Extended Data Fig. $4-1 B$ ), a feature that reflects fast temporal patterning (Cury and Uchida, 2010; Shusterman et al., 2011). Peak amplitude difference distributions for $\Delta C_{t}$ responses were significantly shifted from the diagonal (Wilcoxon signedrank test, $p=2.41 * 10^{-6}$ for $+\Delta C_{t}$ and $p=2.08 * 10^{-8}$ for $-\Delta C_{t}$ responses), while for $C T$ and $C l$ responses the distributions were symmetric about the diagonal (Wilcoxon signed-rank test, $p=0.97$ and $p=0.21$, respectively). Thus, $\Delta C_{t}$ sensitivity also increased contrast at the faster sub-sniff timescale. Lastly, to determine the trial by trial reliability of contrast enhancement by $\Delta C_{t}$ responses, we 
A

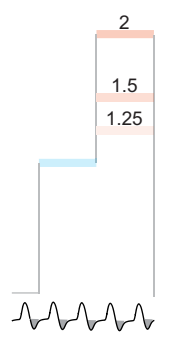

B

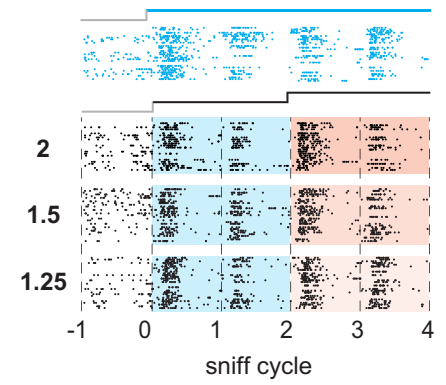

D

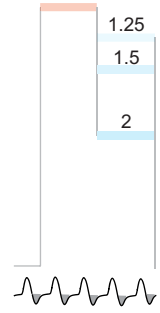

E

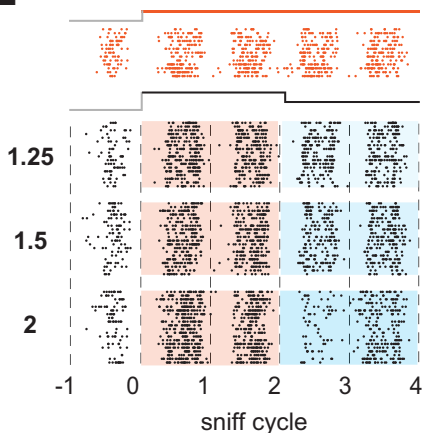

C

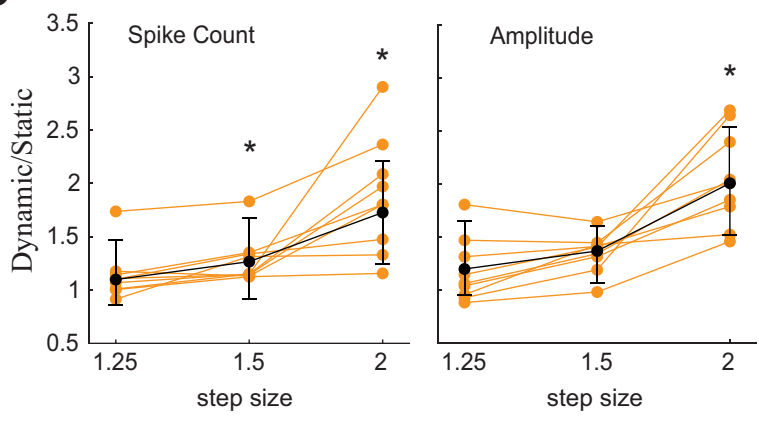

F

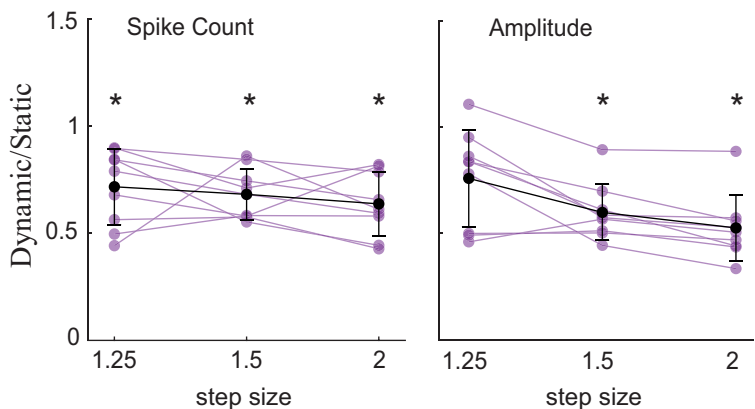

Figure 5. Contrast enhancement is proportional to the magnitude of concentration change step. $\boldsymbol{A}$, Stimulation with positive steps of different size. $\boldsymbol{B}$, Raster plots of $\mathrm{M} / \mathrm{T}$ cell's activity during $\mathrm{L}$ static and three LH dynamic step stimuli. $\boldsymbol{C}$, Normalized changes in spike count and amplitude of the response as function of step size. Orange lines are normalized changes for specific cell-odor pairs, black line is the mean \pm SD change across all responsive cell-odor pairs. Asterisks mark statistically significant deviations from 1 . $\boldsymbol{D}-\boldsymbol{F}$, Same for negative steps.

used receiver operator characteristic $(\mathrm{ROC})$ analysis (see Materials and Methods). In this analysis, $\Delta C_{t}$ responses discriminated better between dynamic and static stimuli than between two static stimuli (Extended Data Fig. 4-2). These analyses demonstrate that $\Delta C_{t}$ sensitivity enhances the contrast between concentrations, potentially facilitating detection of concentration changes.

\section{$\Delta C_{t}$ sensitivity is step magnitude dependent}

We next tested how $\Delta C_{t}$ sensitivity depends on the magnitude of the concentration step. Because 2-fold concentration changes are in the range observed in turbulent plumes (Mylne and Mason, 1991; Crimaldi et al., 2002), and because firing rates fell to near zero in some $-\Delta C_{t}$ responses (Fig. 2C; Extended Data Fig. 2-2), we tested responses to smaller concentration steps. In addition to the twofold steps used in the experiments above, we included a 1.5-fold and a 1.25-fold step, both $\mathrm{LH}$ and $\mathrm{HL}$ (Fig. $5 A, D$ ). To quantify $\Delta C_{t}$ sensitivity, we took the ratio of the response to the dynamic stimulus to that of the static stimulus, for full sniff spike count as well as peak amplitude of the PSTH. $+\Delta C_{t}$ responses (Fig. $5 B$ ) were largest for the 2-fold concentration increase, as expressed by the ratio of the response to the 3rd sniff of the dynamic stimulus $\left(\mathrm{LH}_{3}\right)$ to that of the corresponding static stimulus $\left(\mathrm{H}_{3}\right)$, both for spike count and peak amplitude (Fig. $5 \mathrm{C}$ ). Across the population of $+\Delta C_{t}$ responses, the two larger steps gave significant increases in spike count ( $t$ test; 1.25-fold change: $p=0.72$; 1.5-fold change: $p<0.01$; 2-fold change: $p<0.01$ ), whereas only the largest step evoked a significant increase in peak amplitude: count $(t$ test; 1.25 -fold change: $p=0.5 ; 1.5$-fold change: $p=0.06$; 2 -fold change: $p<0.001$ ). For $-\Delta C_{t}$ responses (Fig. $5 E$ ), spike counts were significantly reduced for all step sizes tested ( $t$ test; 1.25 -fold change: $p<0.01 ; 1.5$-fold change: $p<0.001$; 2-fold change: $p<0.01$; Fig. $5 F$ ), while peak amplitudes were significantly reduced for the two larger steps ( $t$ test; 1.25 -fold change: $p=0.019 ; 1.5$-fold change: $p<0.001$; 2-fold change: $p<0.001$; Fig. $5 F$ ). Thus, larger concentration steps give rise to stronger contrast enhancement.

\section{$\Delta C_{t}$ sensitivity is independent of step duration}

All responses we have shown thus far come from stimuli with steps lasting two sniffs. In natural environments, more rapid variations in odor concentration are common (Murlis et al., 1992). To test the extent to which $\Delta C_{t}$ sensitivity is also evoked by briefer steps, we performed additional experiments in which concentration changed after one sniff (Fig. 6A). To quantify step duration dependent differences in $\Delta C_{t}$ sensitivity, we normalized the peak amplitude (Fig. 6B) and spike count (Fig. 6C) of the $\Delta C_{t}$ responses to the response for the one sniff step. While some responses were step duration dependent (5/13), across the population the differences were not significant (Wilcoxon test; Fig. $6 B, p=0.08$; Fig $6 C, p=0.12$ ). To characterize the extent to which contrast depends on step duration, as above we calculated the ratio of the dynamic 
A
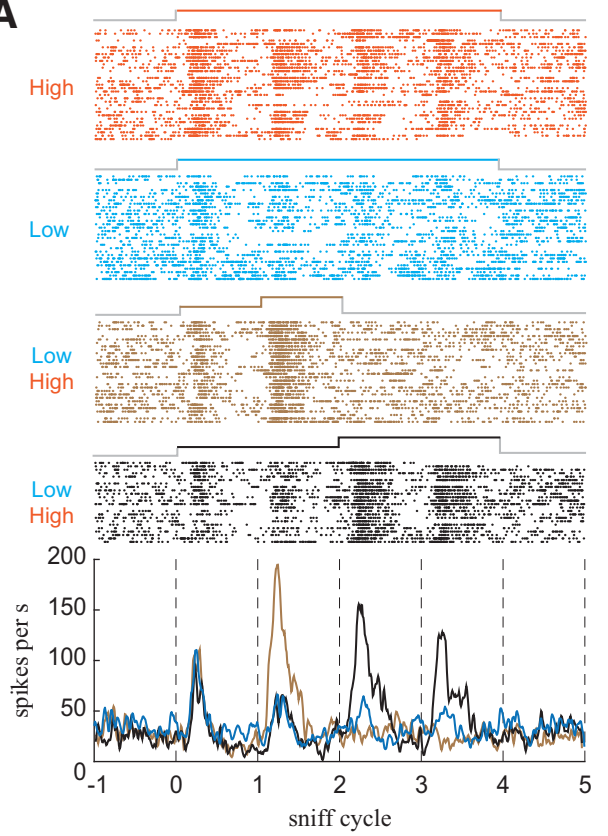

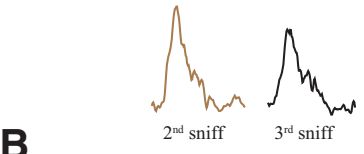

B

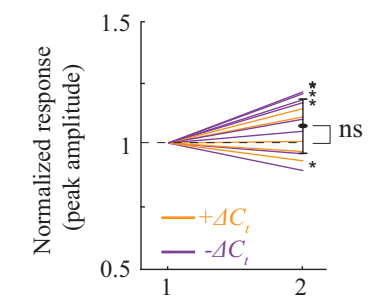

C

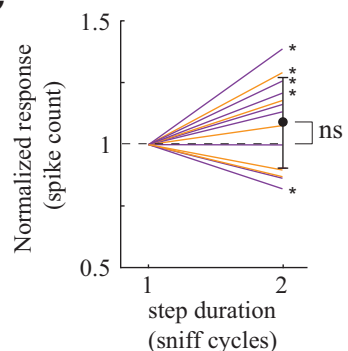

D
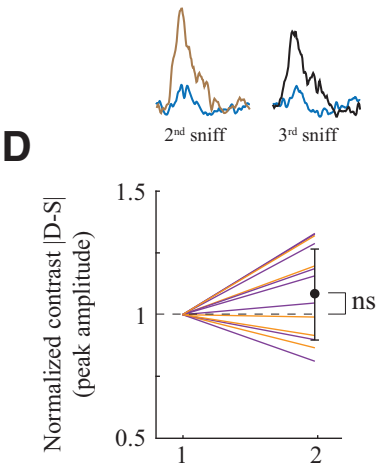

$\mathbf{E}$

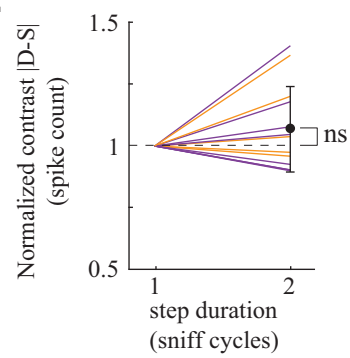

Figure 6. Contrast enhancement is independent of the duration of concentration change step. $\boldsymbol{A}$, Example of $+\Delta C_{t}$ response to two stimuli of different step durations. Raster and PSTH plots of $\mathrm{M} / \mathrm{T}$ cell response to static high concentration (orange), static low concentration (blue), low to high, step duration one sniff (brown), and low to high, two sniffs duration (black). PSTH of response for high static stimulus is not shown for clarity of visualization. $\boldsymbol{B}, \boldsymbol{C}$, Normalized changes in spike count and amplitude of the $+\Delta C_{t}$ responses as function of step duration. Orange lines are normalized changes for $+\Delta C_{t}$ responses, purple lines are for $-\Delta C_{t}$ responses. Asterisks mark responses for which the one-sniff step response and the two-sniff step response differ significantly. $\boldsymbol{D}, \boldsymbol{E}$, Same as $\boldsymbol{B}, \boldsymbol{C}$ for changes in contrast (Idynamic-staticl).

response magnitude to static response magnitude for response amplitude (Fig. 6D) and spike count (Fig. 6E) and normalized this value to that of the one sniff long step. Across the population these differences were not significant (Wilcoxon test; $p=0.16$; Fig. $6 E, p=0.41$; Fig 6D).

\section{Concentration decoding depends on temporal pattern, while $\Delta \boldsymbol{C}_{t}$ decoding does not}

In awake animals, $\mathrm{M} / \mathrm{T}$ cell activity carries information about odor identity (Cury and Uchida, 2010; Shusterman et al., 2011) and intensity (Sirotin et al., 2015) at sub-sniff timescales. To compare how information about concentrations and about changes in concentration might be decoded by downstream olfactory areas, we performed discriminant analysis (see experimental procedures). We first evaluated the accuracy with which responses to two odor concentrations can be discriminated by cell-odor pairs with a $\Delta C_{t}$ response (Fig. 7A). Classification of concentrations was performed on concatenated vectors of firing rates with multiple bin sizes: $5,10,20,40,80$, and $160 \mathrm{~ms}$. Concentration classification performance depended on bin size: smaller bin sizes yielded better discrimination (one-way ANOVA; $p<0.01$; Fig. 7C). Thus, information about odor concentration can be read out most accurately from fine timescale temporal patterns. Using the same classification procedure, we next evaluated whether decoding of concentration changes by the same $\Delta C_{t}$ cell-odor pairs similarly depends on temporal resolution (Fig. 7B). This analysis indicates that decoding of concentration changes is invariant across the full range of bin sizes (one-way ANOVA, $p=0.22$; Fig. 7C). These findings suggest that downstream neurons decode concentration and $\Delta C_{t}$ via different mechanisms.

\section{Discussion}

Studies of freely moving animals have established the importance of odor concentration dynamics in guiding olfactory navigation (Khan et al., 2012; Catania, 2013; Jones and Urban, 2018). While these paradigms have revealed behavioral strategies, odor stimuli in an open field cannot currently be precisely controlled or measured. Without precise knowledge of the stimulus, neuronal responses are difficult to interpret. To achieve precise stimulus control, we have developed a novel system for presenting rapidly changing odor concentration stimuli to head-fixed mice.

Our concentration step stimuli have revealed three response types across cell-odor pairs: (1) CT responses, in which firing rate is proportional to odor concentration on the current sniff, irrespective of concentration in past sniffs; (2) $\mathrm{Cl}$ responses, in which firing rate does not vary across the range of presented odor concentrations; and (3) concentration change sensitive $\left(\Delta C_{t}\right)$ responses, in which firing rate depends not only on the currently-sniffed concentration, but also that of the previous sniff. A given $\mathrm{M} / \mathrm{T}$ cell can give different response types to different odorants. Thus, it does not appear that these response types map onto particular cell types.

$\Delta C_{t}$ responses enhance the contrast between different concentrations, both in fine and coarse timescales. This 
A

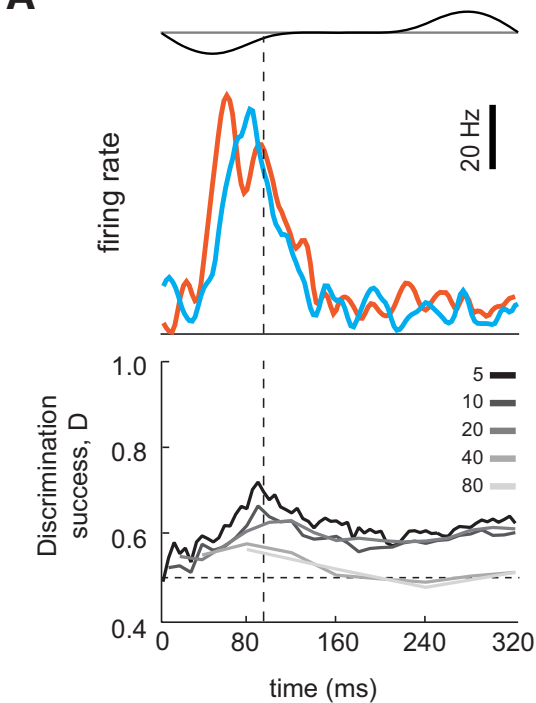

C

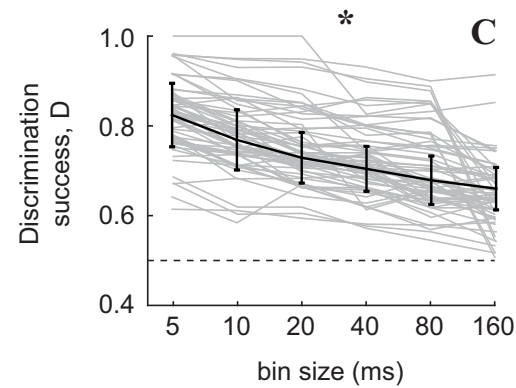

B
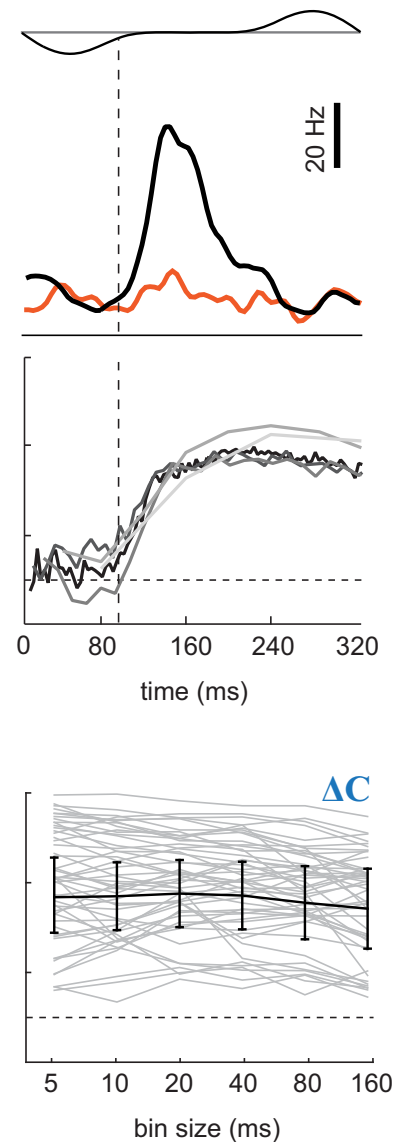

Figure 7. Discrimination among concentrations and changes in concentration by individual M/T cells. $\boldsymbol{A}$, top, PSTHs for a single neuron's responses to two static stimuli (red: high concentration, blue: low concentration). Bottom, corresponding static stimuli discrimination success as a function of time. Vertical dashed lines indicate the end of the inhalation interval. Horizontal dashed lines indicate chance level performance. Different colored traces indicate discrimination success for different bin sizes. B, top, PSTHs for a neuron's responses to a high concentration static stimulus (red), and to a positive concentration step (black). Bottom, Corresponding static stimulus versus step stimulus discrimination success as a function of time. Different colored traces indicate discrimination success for different bin sizes. $\mathbf{C}$, Discrimination performance of a linear classifier between two odor concentrations (left) and between changes in concentration (right) over the 320-ms window, as a function of bin size. Gray lines are performances of individual neurons. Black line is mean \pm SD. Asterisk $(*)$ indicates significant change (one-way ANOVA; $p<0.01$ ) in discrimination success as function of bin size.

contrast enhancement scales with the concentration step magnitude but does not depend on the duration of the step. Lastly, we show that decoding of concentration steps does not depend on the duration of time bins: reading fine timescale features does not improve classification performance.

Taken together, we have obtained the first evidence that neurons in the mammalian olfactory system represent inter-sniff changes in odor concentration. Such temporal contrast enhancement is widespread in other sensory modalities, consistent with the paramount importance of sensing stimulus dynamics. Furthermore, we find that this representation is already present near the sensory periphery, in the olfactory bulb. Computing $\Delta C_{t}$ near the periphery allows the signal to be broadcast to the OB's numerous targets in the cortex.

\section{Neuronal mechanisms of $\Delta C_{t}$ sensitivity}

Invertebrate olfactory organs sample incoming odors continuously, so that their OSNs are directly exposed to gradients of odor concentration (Nagel and Wilson, 2011; Kim et al., 2015; Schulze et al., 2015), as well as intermittent intensity fluctuations found in plumes (Vickers et al., 2001). In contrast, terrestrial vertebrates such as mice sample odors intermittently. To compare the intensities of the previous and the current inhalation, the animal must preserve a representation of the previous concentration during the exhalation interval. A simple way in which information can persist over time is through historydependent adaptation. Adaptation allows cells to match their limited dynamic range to the distribution of stimulus intensities in the environment (Kohn, 2007). We propose that the function of $\Delta C_{t}$ responses is to shift the dynamic range of olfactory neurons to increase sensitivity to concentrations close to the recently inhaled stimulus. A similar adjustment of dynamic range has been observed for motion processing in the insect visual system (Fairhall et al., 2001). Mechanistically, shifts in dynamic range may be implemented via intrinsic neuronal properties, such as spike threshold adaptation (Henze and Buzsáki, 2001; 
Itskov et al., 2011) Alternatively, $\Delta C_{t}$ sensitivity may be achieved by circuit mechanisms, such as intrabulbar interactions (Shepherd and Greer, 1998; Wachowiak and Shipley, 2006; Burton, 2017) or cortical feedback (Luskin and Price, 1983; Li and Hopfield, 1989; Boyd et al., 2012; Markopoulos et al., 2012; Boyd et al., 2015; Otazu et al., 2015).

A cell with $\Delta C_{t}$ sensitivity to one odor can have a different response type to another effective odor. This eliminates the possibility that a dedicated population of " $\Delta C_{t}$ cells" represents $\Delta C_{t}$ irrespective of odor identity and absolute concentration. Similarly, malleable stimulus selectivity has been observed in other sensory systems. For example, in the retina, although it is widely accepted that retinal ganglion cells consist of dedicated cell types with selectivity for a particular visual feature, recent work challenges this view (Rivlin-Etzion et al., 2018; Wienbar and Schwartz, 2018). Identified ON or OFF retinal ganglion cells can change their polarity based on stimulation outside the receptive field (Geffen et al., 2007) and ambient light levels (Tikidji-Hamburyan et al., 2015). Directionselective ganglion cells can reverse their preferred direction of motion depending on recent stimulus history (Rivlin-Etzion et al., 2012). Thus, even classic "feature detector" cell types of the retina can change their selectivity under different conditions. As with other sensory features, understanding $\Delta C_{t}$ processing will require a more thorough exploration of stimulus space, in as close to natural conditions as possible.

\section{Potential relevance of $\Delta C_{t}$ sensitivity in the natural environment}

Odor concentration gradients are critical for odor source localization (Murlis et al., 1992). Mice must locate odor sources in various airflow conditions, which will largely determine the spatiotemporal statistics of odor concentration. Turbulence disrupts concentration gradients emanating from a distant odor source (Murlis et al., 1990, 1992; Weissburg, 2000). However, even in turbulent flow, gradients, and therefore $\Delta C_{t}$, become increasingly informative closer to the source (Justus et al., 2002; Riffell et al., 2008; Gire et al., 2016). Therefore, when following a plume from a nearby source (Catania, 2013; Gire et al., 2016), or when tracking a depositional odor trail (Khan et al., 2012; Jones and Urban, 2018), $\Delta C_{t}$ signals can guide the nose.

In the real world, there may also be odor fluctuations faster than the inhalation time scale. We argue that temporal changes in odor concentration on the sub-sniff scale are not relevant, due to several slow processes. First, based on the physics of the nasal cavity, odor fluctuations will be low pass filtered (Doebelin, 1990). Second, the odorant molecules must transition from air to liquid and diffuse through the mucus (Hahn et al., 1994). Lastly, the flicker fusion frequency of mouse OSNs in vitro is $3-5 \mathrm{~Hz}$ (Ghatpande and Reisert, 2011). Because of these slow processes, we think it is unlikely that sub-sniff timescale changes in odor concentration are available to the olfactory system.

Vertebrates sense gradients by stereo (inter-naris) and serial (inter-sniff) comparisons (Rajan et al., 2006; Catania,
2013). Because the nares are close together, stereo comparison should be most informative near an odor source, where odor gradients are steep. Shallower gradients, farther from a source, may require the inter-sniff comparison, since the distance between sampling locations can be larger than the inter-naris distance (Catania, 2013). In a turbulent environment with noisy gradients (Gire et al., 2016), comparison over more than two sniff cycles may be required. While stereo comparisons have been studied both behaviorally (Rajan et al., 2006; Porter et al., 2007; Catania, 2013) and electrophysiologically (Rajan et al., 2006; Kikuta et al., 2010), the serial component, which should dominate over a wider range of distances, has not been explored. Our study demonstrates a neural representation of $\Delta C_{t}$. We propose that this representation contributes to olfactory search in natural olfactory scenes.

\section{References}

Ache BW, Hein AM, Bobkov YV, Principe JC (2016) Smelling time: a neural basis for olfactory scene analysis. Trends Neurosci 39:649655. CrossRef Medline

Bodyak N, Slotnick B (1999) Performance of mice in an automated olfactometer: odor detection, discrimination and odor memory. Chem Senses 24:637-645. CrossRef

Bolding KA, Franks KM (2018) Recurrent cortical circuits implement concentration-invariant odor coding. Science. 361: eaat6904. CrossRef Medline

Boyd AM, Sturgill JF, Poo C, Isaacson JS (2012) Cortical feedback control of olfactory bulb circuits. Neuron 76:1161-1174. CrossRef Medline

Boyd AM, Kato HK, Komiyama T, Isaacson JS (2015) Broadcasting of cortical activity to the olfactory bulb. Cell Rep 10:1032-1039. CrossRef Medline

Bregman AS (1994) Auditory scene analysis. Cambridge, MA: MIT Press.

Burton SD (2017) Inhibitory circuits of the mammalian main olfactory bulb. J Neurophysiol 118:2034-2051. CrossRef Medline

Cang J, Isaacson JS (2003) In vivo whole-cell recording of odorevoked synaptic transmission in the rat olfactory bulb. J Neurosci 23:4108-4116. CrossRef Medline

Catania KC (2013) Stereo and serial sniffing guide navigation to an odour source in a mammal. Nat Commun 4:1441. CrossRef Medline

Crimaldi JP, Wiley MB, Koseff JR (2002) The relationship between mean and instantaneous structure in turbulent passive scalar plumes. J Turbul 3. CrossRef

Cury KM, Uchida N (2010) Robust odor coding via inhalationcoupled transient activity in the mammalian olfactory bulb. Neuron 68:570-585. CrossRef Medline

Doebelin EO (1990) Measurement systems: application and design. New York: McGraw-Hill.

Fairhall AL, Lewen GD, Bialek W, van Steveninck R (2001) Efficiency and ambiguity in an adaptive neural code. 412:787-792. CrossRef Medline

Gaudry Q, Nagel KI, Wilson RI (2012) Smelling on the fly: sensory cues and strategies for olfactory navigation in Drosophila. Curr Opin Neurobiol 22:216-222. CrossRef Medline

Geffen MN, de Vries SEJ, Meister M (2007) Retinal ganglion cells can rapidly change polarity from off to on. PLoS Biol 5:e65. CrossRef Medline

Ghatpande AS, Reisert J (2011) Olfactory receptor neuron responses coding for rapid odour sampling. J Physiol 589:2261-2273. CrossRef Medline

Gire DH, Kapoor V, Arrighi-Allisan A, Seminara A, Murthy VN (2016) Mice develop efficient strategies for foraging and navigation using complex natural stimuli. Curr Biol 26:1261-1273. CrossRef Medline 
Green DM, Swets JA (1966) Signal detection theory and psychophysics. Oxford, UK: Wiley.

Hahn I, Scherer PW, Mozell MM (1994) A mass transport model of olfaction. J Theor Biol 167:115-128. CrossRef Medline

Henze DA, Buzsáki G (2001) Action potential threshold of hippocampal pyramidal cells in vivo is increased by recent spiking activity. Neuroscience 105:121-130. CrossRef Medline

Itskov V, Curto C, Pastalkova E, Buzsáki G (2011) Cell assembly sequences arising from spike threshold adaptation keep track of time in the hippocampus. J Neurosci 31:2828-2834. CrossRef Medline

Jones PW, Urban NN (2018) Mice follow odor trails using stereo olfactory cues and rapid sniff to sniff comparisons. bioRxiv 1-24. CrossRef

Justus KA, Murlis J, Jones C, Cardé RT (2002) Measurement of odor-plume structure in a wind tunnel using a photoionization detector and a tracer gas. Environ Fluid Mech 2:115-142. CrossRef

Khan AG, Sarangi M, Bhalla US (2012) Rats track odour trails accurately using a multi-layered strategy with near-optimal sampling. Nat Commun 3:703. CrossRef Medline

Kikuta S, Sato K, Kashiwadani H, Tsunoda K, Yamasoba T, Mori K (2010) From the cover: neurons in the anterior olfactory nucleus pars externa detect right or left localization of odor sources. Proc Natl Acad Sci USA 107:12363-12368. CrossRef Medline

Kim AJ, Lazar AA, Slutskiy YB (2015) Projection neurons in Drosophila antennal lobes signal the acceleration of odor concentrations. Elife 4: e06651. CrossRef Medline

Kohn A (2007) Visual adaptation: physiology, mechanisms, and functional benefits. J Neurophysiol 97:3155-3164. CrossRef Medline

Kuffler SW (1953) Discharge patterns and functional organization of mammalian retina. J Neurophysiol 16:37-68. CrossRef Medline

Langner G (1992) Periodicity coding in the auditory system. Hear Res 60:115-142. CrossRef Medline

Li Z, Hopfield JJ (1989) Modeling the olfactory bulb and its neural oscillatory processings. Biol Cybern 61:379-392. CrossRef Medline

Luskin MB, Price JL (1983) The topographic organization of associational fibers of the olfactory system in the rat, including centrifugal fibers to the olfactory bulb. J Comp Neurol 216:264-291. CrossRef Medline

Markopoulos F, Rokni D, Gire DH, Murthy VN (2012) Functional properties of cortical feedback projections to the olfactory bulb. Neuron 76:1175-1188. CrossRef Medline

Martelli C, Carlson JR, Emonet T (2013) Intensity invariant dynamics and odor-specific latencies in olfactory receptor neuron response. J Neurosci 33:6285-6297. CrossRef Medline

Mountcastle VB, Talbot WH, Darian-Smith I, Kornhuber HH (1967) Neural basis of the sense of flutter-vibration. Science 155:597600. CrossRef Medline

Murlis J, Willis MA, Carde RT (1990) Odour signals: patterns in time and space. Proceedings of the Tenth International Symposium on Olfaction and Taste. GCS A/S, Oslo, Norway.

Murlis J, Elkinton JS, Cardé RT (1992) Odor plumes and how insects use them. Annu Rev Entomol 37:505-532. CrossRef

Mylne KR, Mason PJ (1991) Concentration fluctuation measurements in a dispersing plume at a range of up to $1000 \mathrm{~m}$. Quart J Roy Meteorol Soc 117:177-206. CrossRef

Nagel KI, Wilson RI (2011) Biophysical mechanisms underlying olfactory receptor neuron dynamics. Nat Neurosci 14:208-216. CrossRef Medline

Otazu GH, Chae H, Davis MB, Albeanu DF (2015) Cortical feedback decorrelates olfactory bulb output in awake mice. Neuron 86: 1461-1477. CrossRef Medline

Porter J, Craven B, Khan RM, Chang S-J, Kang I, Judkewitz B, Judkewicz B, Volpe J, Settles G, Sobel N (2007) Mechanisms of scent-tracking in humans. Nat Neurosci 10:27-29. CrossRef Medline

Rajan R, Clement JP, Bhalla US (2006) Rats smell in stereo. Science 311:666-670. CrossRef Medline
Ratliff F, Hartline HK, Miller WH (1963) Spatial and temporal aspects of retinal inhibitory interaction. J Opt Soc Am 53:110-120. Medline

Resulaj A, Rinberg D (2015) Novel behavioral paradigm reveals lower temporal limits on mouse olfactory decisions. J Neurosci 35: 11667-11673. CrossRef Medline

Riffell JA, Abrell L, Hildebrand JG (2008) Physical processes and real-time chemical measurement of the insect olfactory environment. J Chem Ecol 34:837-853. CrossRef Medline

Rivlin-Etzion M, Grimes WN, Rieke F (2018) Flexible neural hardware supports dynamic computations in retina. Trends Neurosci 41: 224-237. CrossRef Medline

Rivlin-Etzion M, Wei W, Feller MB (2012) Visual stimulation reverses the directional preference of direction-selective retinal ganglion cells. Neuron 76:518-525. CrossRef Medline

Schiller PH (1992) The ON and OFF channels of the visual system. Trends Neurosci 15:86-92. CrossRef Medline

Schulze A, Gomez-Marin A, Rajendran VG, Lott G, Musy M, Ahammad P, Deogade A, Sharpe J, Riedl J, Jarriault D, Trautman ET, Werner C, Venkadesan M, Druckmann S, Jayaraman V, Louis M (2015) Dynamical feature extraction at the sensory periphery guides chemotaxis. Elife 4:e06694. CrossRef Medline

Shepherd GM, Greer CA (1998) Olfactory bulb. In: The synaptic organization of the brain (Shepherd GM, ed), pp 159-203. New York, NY: Oxford University Press.

Shusterman R, Smear MC, Koulakov AA, Rinberg D (2011) Precise olfactory responses tile the sniff cycle. Nat Neurosci 14:10391044. CrossRef Medline

Shusterman R, Sirotin YB, Smear MC, Ahmadian Y, Rinberg D (2018) Sniff invariant odor coding. eNeuro 5: ENEURO.0149-18.2018. CrossRef Medline

Sirotin YB, Shusterman R, Rinberg D (2015) Neural coding of perceived odor intensity. eNeuro 2: ENEURO.0083-15.2015. CrossRef Medline

Smear M, Shusterman R, O'Connor R, Bozza T, Rinberg D (2011) Perception of sniff phase in mouse olfaction. Nature 479:397-400. CrossRef Medline

Tikidji-Hamburyan A, Reinhard K, Seitter H, Hovhannisyan A, Procyk CA, Allen AE, Schenk M, Lucas RJ, Münch TA (2015) Retinal output changes qualitatively with every change in ambient illuminance. Nat Neurosci 18:66-74. CrossRef Medline

Verhagen JV, Wesson DW, Netoff TI, White JA, Wachowiak M (2007) Sniffing controls an adaptive filter of sensory input to the olfactory bulb. Nat Neurosci 10:631-639. CrossRef Medline

Vickers NJ, Christensen TA, Baker TC, Hildebrand JG (2001) Odourplume dynamics influence the brain's olfactory code. 410:466470. CrossRef Medline

Wachowiak M, Shipley MT (2006) Coding and synaptic processing of sensory information in the glomerular layer of the olfactory bulb. Semin Cell Dev Biol 17:411-423. CrossRef Medline

Weissburg MJ (2000) The fluid dynamical context of chemosensory behavior. Biol Bull 198:188-202. CrossRef Medline

Werner G, Mountcastle VB (1965) Neural activity in mechanoreceptive cutaneous afferents: stimulus-response relations, weber functions, and information transmission. J Neurophysiol 28:359-397. CrossRef Medline

Wertheimer M (1912) Experimentelle Studien über das Sehen von Bewegung. Zeitschrift fur Psychologie 61.

Westheimer G (2007) The ON-OFF dichotomy in visual processing: from receptors to perception. Prog Retin Eye Res 26:636-648. CrossRef Medline

Wienbar S, Schwartz GW (2018) The dynamic receptive fields of retinal ganglion cells. Prog Retin Eye Res 67:102-117. CrossRef Medline

Wilson CD, Serrano GO, Koulakov AA, Rinberg D (2017) A primacy code for odor identity. Nat Commun 8:1477. CrossRef Medline

Wilson RI, Mainen ZF (2006) Early events in olfactory processing. Annu Rev Neurosci 29:163-201. CrossRef Medline

Wojcik PT, Sirotin YB (2014) Single scale for odor intensity in rat olfaction. Curr Biol 24:568-573. CrossRef Medline 